\title{
NORMOXIC CARDIOPULMONARY BYPASS REDUCES OXIDATIVE MYOCARDIAL DAMAGE AND NITRIC OXIDE DURING CARDIAC OPERATIONS IN THE ADULT
}

Kai Ihnken, MD

Anke Winkler, MD

Christian Schlensak, MD

Koppy Sarai, MD

Gerd Neidhart, MD

Uwe Unkelbach, MD

Alexander Mülsch, MD

Adrian Sewell, PhD
Objective: Hyperoxic cardiopulmonary bypass is widely used during cardiac operations in the adult. This management may cause oxygenation injury induced by oxygen-derived free radicals and nitric oxide. Oxidative damage may be significantly limited by maintaining a more physiologic oxygen tension strategy (normoxic cardiopulmonary bypass). Methods: During elective coronary artery bypass grafting, 40 consecutive patients underwent either hyperoxic (oxygen tension $=400 \mathrm{~mm} \mathrm{Hg}$ ) or normoxic (oxygen tension = $140 \mathrm{~mm} \mathrm{Hg}$ ) cardiopulmonary bypass. At the beginning and the end of bypass this study assessed polymorphonuclear leukocyte elastase, nitrate, creatine kinase, and lactic dehydrogenase, antioxidant levels, and malondialdehyde in coronary sinus blood. Cardiac index was measured before and after cardiopulmonary bypass. Results: There was no difference between groups with regard to age, sex, severity of disease, ejection fraction, number of grafts, duration of cardiopulmonary bypass, or ischemic time. Hyperoxic bypass resulted in higher levels of polymorphonuclear leukocyte elastase $(377 \pm 34 \mathrm{vs} 171 \pm 32 \mathrm{ng} / \mathrm{ml}, p=0.0001)$, creatine kinase $672 \pm$ 130 vs $293 \pm 21 \mathrm{U} / \mathrm{L}, p=0.002)$, lactic dehydrogenase $(553 \pm 48$ vs $301 \pm$ $12 \mathrm{U} / \mathrm{L}, p=0.003)$, antioxidants $(1.97 \pm 0.10 \mathrm{vs} 1.41 \pm 0.11 \mathrm{mmol} / \mathrm{L}, p=$ $0.01)$, malondialdehyde $(1.36 \pm 0.1 \mu \mathrm{mol} / \mathrm{L}, p=0.005)$, and nitrate $(19.3 \pm$ 2.9 vs $10.1 \pm 2.1 \mu \mathrm{mol} / \mathrm{L}, p=0.002$ ), as well as reduction in lung vital capacity $(66 \% \pm 2 \%$ vs $81 \% \pm 1 \%, p=0.01)$ and forced 1 -second expiratory volume $(63 \% \pm 10 \%$ vs $93 \% \pm 4 \%, p=0.005)$ compared with normoxic management. Cardiac index after cardiopulmonary bypass at low filling pressure was similar between groups $(3.1 \pm 0.2$ vs $3.3 \pm 0.3 \mathrm{~L} / \mathrm{min}$ per square meter). [Data are mean \pm standard error (analysis of variance), with $p$ values compared with an oxygen tension of $400 \mathrm{~mm} \mathrm{Hg.]} \mathrm{Conclusions:}$ Hyperoxic cardiopulmonary bypass during cardiac operations in adults results in oxidative myocardial damage related to oxygen-derived free radicals and nitric oxide. These adverse effects can be markedly limited by reduced oxygen tension management. The concept of normoxic cardiopulmonary bypass may be applied to surgical advantage during cardiac operations. (J Thorac Cardiovasc Surg 1998;116:327-34)
From the Department of Cardiothoracic and Vascular Surgery, Johann-Wolfgang-Goethe University (Chairman: Peter Satter, MD, Professor of Surgery), Frankfurt, Germany.

Received for publication August 26, 1997; revisions requested Nov. 3, 1997; revisions received March 10, 1998; accepted for publication March 25, 1998.

Address for reprints: Kai Ihnken, MD, Stanford University Hospital, Department of Surgery, Room H3680, 300 Pasteur Dr., Stanford, CA 94305.

Copyright (c) 1998 by Mosby, Inc.

$0022-5223 / 98 \$ 5.00+0 \quad \mathbf{1 2 / 1 / 9 0 6 7 0}$
D uring surgical interventions of the normoxic adult heart, cardiopulmonary bypass (CPB) is commonly instituted in a hyperoxic fashion (oxygen tension $\left[\mathrm{PO}_{2}\right] 300$ to $400 \mathrm{~mm} \mathrm{Hg}$ ) without considering the toxic potentials of high levels of molecular oxygen. Our previous studies have demonstrated that hyperoxic CPB may lead to a myocardial reoxygenation injury in hypoxic immature hearts. ${ }^{1,2}$ The relevance of these findings is reinforced by clinical reports showing myocardial lipid peroxidation in preischemic myocardial biopsy samples from cyanotic children ${ }^{3}$ and myocardial dysfunction in hypoxic infants undergoing 


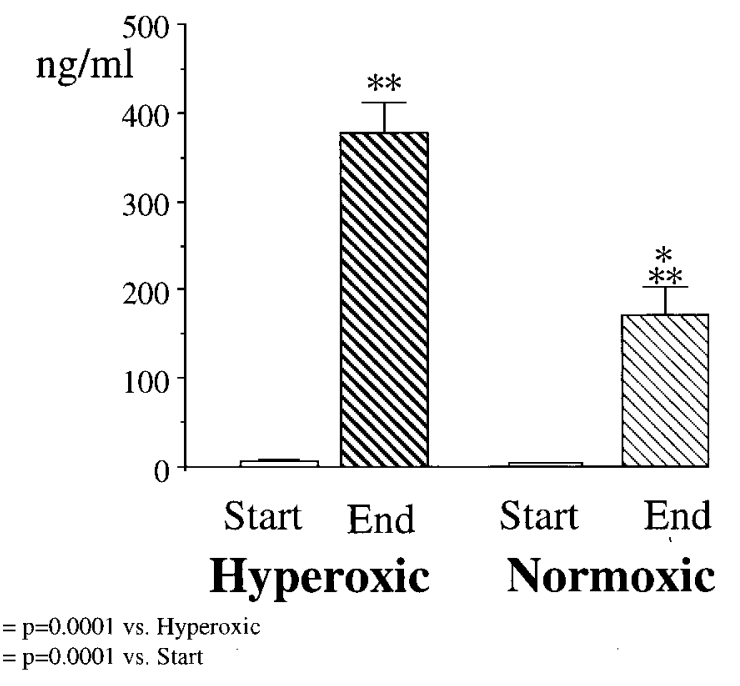

Fig. 1. PMN elastase in coronary sinus blood at the start and end of $\mathrm{CPB}$ in comparison of patients undergoing hyperoxic $\left(\mathrm{Po}_{2}=400 \mathrm{~mm} \mathrm{Hg}\right)$ or normoxic $\left(\mathrm{Po}_{2}=140\right.$ $\mathrm{mm} \mathrm{Hg)} \mathrm{CPB.}$

extracorporeal membrane oxygenation without surgical ischemia. ${ }^{4}$

Oxygen-derived free radicals and nitric oxide (NO)-derived peroxinitrite play an important role in the development of hyperoxic damage. ${ }^{5,6}$ This assumption is partly based on the beneficial effect of treatment with oxygen-derived free radical scavengers ${ }^{7,8}$ and by direct evidence of increased levels of oxygen-derived free radicals during reoxygenation. ${ }^{9}$ The rate of production of these highly reactive toxic oxygen species is dependent on the oxygen level during reoxygenation and on cellular oxygen metabolism. ${ }^{10,11}$ In their early studies, Hearse, Humphrey, and Bullock ${ }^{12}$ could demonstrate that lowering $\mathrm{PO}_{2}$ during reoxygenation was followed by less release of myocardial creatine kinase. ${ }^{12}$ Further investigations found similar results in organs other than the heart. ${ }^{11,13} \mathrm{We}^{14}$ introduced the concept of normoxic CPB in hypoxemic immature hearts to avoid myocardial damage after hyperoxia. The present clinical study of normoxic adult hearts supported by CPB tests the hypothesis that reduction of oxygen concentration in the circuit of the extracorporeal circulation to normoxic levels can reduce the damaging effects of hyperoxia and will result in an improved postoperative myocardial status.

\section{Patients and methods}

Patients. Included in the study were 40 consecutive patients scheduled for elective coronary artery bypass
Table I. Clinical characteristics and intraoperative and postoperative data of the patient groups undergoing either hyperoxic or normoxic $C P B$

\begin{tabular}{lccl}
\hline & Hyperoxic & Normoxic & $p$ Value \\
\hline No. of patients & 20 & 20 & \\
Male & 16 & 17 & \\
Female & 4 & 3 & \\
Inotropic support (No.) & 4 & 2 & \\
Smokers (No.) & 14 & 12 & \\
Diabetes mellitus (No.) & 5 & 7 & \\
Age (yr) & $61 \pm 2$ & $63 \pm 2$ & 0.4 \\
Ejection fraction (\%) & $61 \pm 5$ & $61 \pm 6$ & 0.9 \\
Po $_{2}$ on CPB (mm Hg) & $419 \pm 13$ & $142 \pm 9$ & 0.0001 \\
No. of grafts & $3 \pm 0.1$ & $3 \pm 0.1$ & 0.9 \\
CPB time (min) & $82 \pm 4$ & $81 \pm 3$ & 0.9 \\
Ischemic time (min) & $53 \pm 2$ & $52 \pm 2$ & 0.6 \\
Ventilator support (hr) & $22 \pm 8$ & $14 \pm 1$ & 0.2 \\
Days in ICU & $1.9 \pm 0.1$ & $1.6 \pm 0.2$ & 0.08 \\
Days in hospital & $9.6 \pm 0.5$ & $8.6 \pm 0.3$ & 0.06 \\
\hline
\end{tabular}

$C P B$, Cardiopulmonary bypass; $\mathrm{PO}_{2}$, oxygen tension; $\mathrm{ICU}$, intensive care unit.

grafting between July and October of 1996 and operated on by the same surgeon. They were randomized to encounter either hyperoxic $\left(\mathrm{PO}_{2}=400 \mathrm{~mm} \mathrm{Hg}\right)$ or normoxic $\left(\mathrm{PO}_{2}=140 \mathrm{~mm} \mathrm{Hg}\right) \mathrm{CPB}$, with the surgeon and the intensive care unit staff blinded to the assignment. The study was approved by the ethics committee of the Johann-Wolfgang-Goethe University, Frankfurt, Germany. Informed consent was obtained from patients before they were included in the study.

CPB and myocardial protection. After induction of general anesthesia and systemic application of heparin (300 IU/kg body weight), CPB (Stöckert Instrumente, München, Germany) was initiated in a standard fashion. Moderate body hypothermia $\left(28^{\circ}\right.$ to $\left.32^{\circ} \mathrm{C}\right)$ was used. The coronary sinus was cannulated (Research Medical Inc., Salt Lake City, Utah) and antegrade/retrograde blood cardioplegic arrest was used in all patients as described elsewhere. ${ }^{15}$ One group of patients underwent hyperoxic $\mathrm{CPB}\left(\mathrm{PO}_{2}=400 \mathrm{~mm} \mathrm{Hg}\right)$ (normal clinical practice) and the other group underwent normoxic $\mathrm{CPB}\left(\mathrm{PO}_{2}=140 \mathrm{~mm}\right.$ $\mathrm{Hg}$ ). Arterial oxygen levels were measured by means of an in-line oxygen determination device (Extracorporeal Blood Gas Monitoring System 300, Cardiovascular Devices Inc., Irvine, Calif.). Other than the oxygen content during $\mathrm{CPB}$, the patient management was the same for both groups. After the patients had been rewarmed to a core temperature of at least $35^{\circ} \mathrm{C}, \mathrm{CPB}$ was discontinued and protamine given for heparin reversal.

Blood samples and measurements. Samples of coronary sinus blood (for determination of polymorphonuclear leukocyte [PMN] elastase, creatine kinase, lactic dehydrogenase, antioxidant levels, malondialdehyde, nitrate, and glucose) and systemic venous blood (for lactate, $\mathrm{pH}, \mathrm{PO}_{2}$, and $\mathrm{PCO}_{2}$ ) were taken at the beginning and at the end of CPB. PMN elastase was measured by means of an immunoassay (Merck, Darmstadt, Germany). Creatine kinase, lactic dehydrogenase, lactate, and glucose determinations were done by means of test kits (Boehringer 
$\mathrm{U} /$

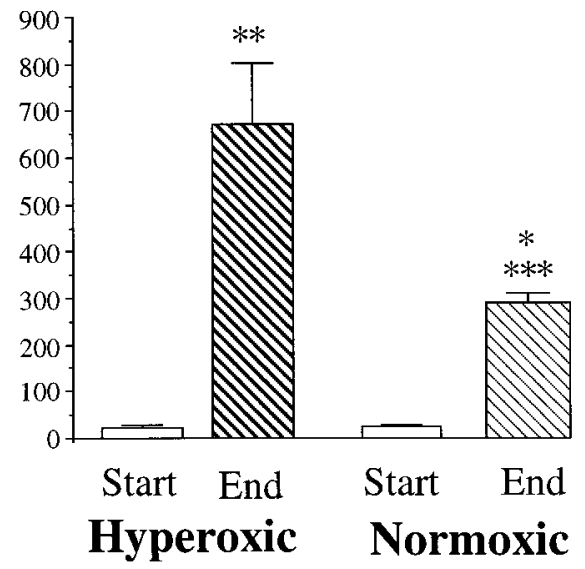

$*=p=0.0002$ vs. Hyperoxic

$* *=\mathrm{p}=0.0001$ vs. Start

$* * *=p=0.0002 \mathrm{vs}$. Start

Fig. 2. Creatine kinase in coronary sinus blood at the start and end of $\mathrm{CPB}$ in comparison of patients undergoing hyperoxic $\left(\mathrm{PO}_{2}=400 \mathrm{~mm} \mathrm{Hg}\right)$ or normoxic $\left(\mathrm{PO}_{2}=\right.$ $140 \mathrm{~mm} \mathrm{Hg}$ ) CPB.

Mannheim GmbH, Mannheim, Germany). Blood antioxidant status was determined according to the method of Miller and colleagues. ${ }^{16}$ This test measures the total plasma antioxidant activity without differentiating between individual contribution of plasma antioxidants (i.e., ascorbate, protein thiols, bilirubin, urate, and $\alpha$-tocopherol). ${ }^{16}$ Malondialdehyde was determined by the method described by Wong and coauthors. ${ }^{17}$ Nitrate was measured after reduction to nitrite as described by Green and colleagues. ${ }^{18}$

Cardiopulmonary measurements. A Swan-Ganz pulmonary artery catheter (Baxter Healthcare Corp., Edwards Division, Santa Ana, Calif.) was inserted for measurement of pulmonary artery and pulmonary capillary wedge pressure and for measurement of cardiac output. Hemodynamic measurements were made before starting the surgical procedure and after skin closure. Cardiac index $\left(\mathrm{L} / \mathrm{min} / \mathrm{m}^{2}\right)$ is cardiac output $(\mathrm{L} / \mathrm{min})$ divided by body surface area $\left(\mathrm{m}^{2}\right)$. Pulmonary vascular resistance index (PVRI) was calculated by means of the following equation: PVRI $\left(\mathrm{mm} \mathrm{Hg} \times \min \times \mathrm{L}^{-1} \times \mathrm{kg}\right)=(\mathrm{PAP}-$ LAP) $(\mathrm{mm} \mathrm{Hg}) \times \mathrm{CO}^{-1}(\mathrm{ml} / \mathrm{min}) \times \mathrm{BW}(\mathrm{kg})$, where PAP is pulmonary artery pressure, LAP is left atrial pressure, $\mathrm{CO}$ is cardiac output, and $\mathrm{BW}$ is body weight.

Pulmonary function tests were done 1 day before and 5 days after the operation. Measurements included vital capacity, forced vital capacity, forced expiratory volume in the first second, and maximum expiratory flow at 50\% vital capacity. The results are given as percent of normal values, corrected for sex, age, and body surface area.

Statistical analysis. Statistical analysis was done in cooperation with the Statistical Department of the AlbertLudwigs-University Freiburg, Germany. Data were analyzed with StatView V2.0 on an Apple Macintosh IICi computer. Analysis of variance was used for overall com-

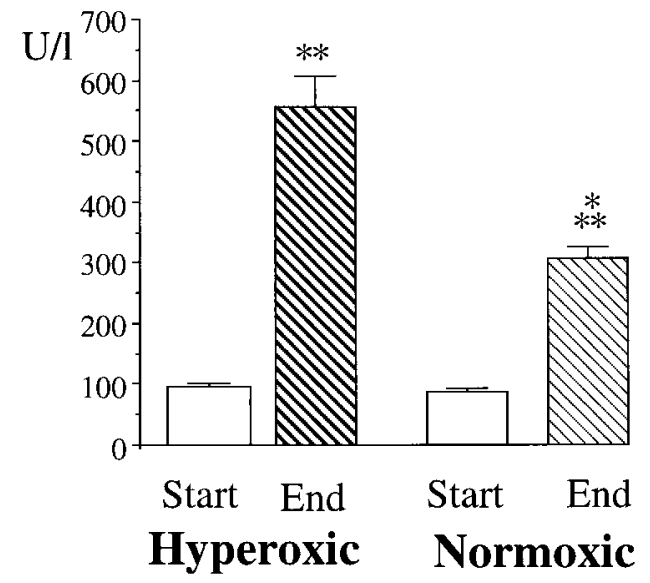

$*=\mathrm{p}=0.003$ vs. Hyperoxic

$* *=p=0.0001$ vs. Start

Fig. 3. Lactic dehydrogenase in coronary sinus blood at the start and end of $\mathrm{CPB}$ in comparison of patients undergoing hyperoxic $\left(\mathrm{PO}_{2}=400 \mathrm{~mm} \mathrm{Hg}\right)$ or normoxic $\left(\mathrm{PO}_{2}=140 \mathrm{~mm} \mathrm{Hg}\right) \mathrm{CPB}$.

parison. Differences between individual groups were evaluated by $t$ test and Scheffe F test. The end-CPB values were used unless stated otherwise. The paired two-tailed Student's $t$ test was used for comparison of repeatedly documented variables within experimental groups. Group data are expressed as mean \pm standard deviation.

\section{Results}

General. The groups did not differ in terms of age, sex, severity of disease, comorbidity, ejection fraction, number of grafts, duration of $\mathrm{CPB}$ or ischemia, and days in the intensive care unit. The hospital stay of the hyperoxic group averaged 1 day longer than that of the normoxic group $(p=0.06)$. The hyperoxic patients needed $57 \%$ longer duration of ventilator support, but due to the larger standard deviation this did not reach a statistically significant level $(p=0.2)$. The absolute values are displayed in Table I. Values of calcium potassium, sodium, hematocrit, hemoglobin, erythrocytes, leukocytes, and thrombocytes showed no differences between groups (data not shown). The oxygen level in the extracorporeal circulation was $419 \pm 13 \mathrm{~mm} \mathrm{Hg}$ in the hyperoxic group and $142 \pm 9 \mathrm{~mm} \mathrm{Hg}$ in normoxic patients ( $p=0.0001$ vs hyperoxic).

Biochemical. PMN elastase increased 67-fold (hyperoxic) and 55-fold (normoxic) at the end of CPB compared with start-CPB values $(p=0.0001)$. End-CPB values were higher in the hyperoxic group $(p=0.0001$ vs normoxic). The absolute values are shown in Fig. 1. 


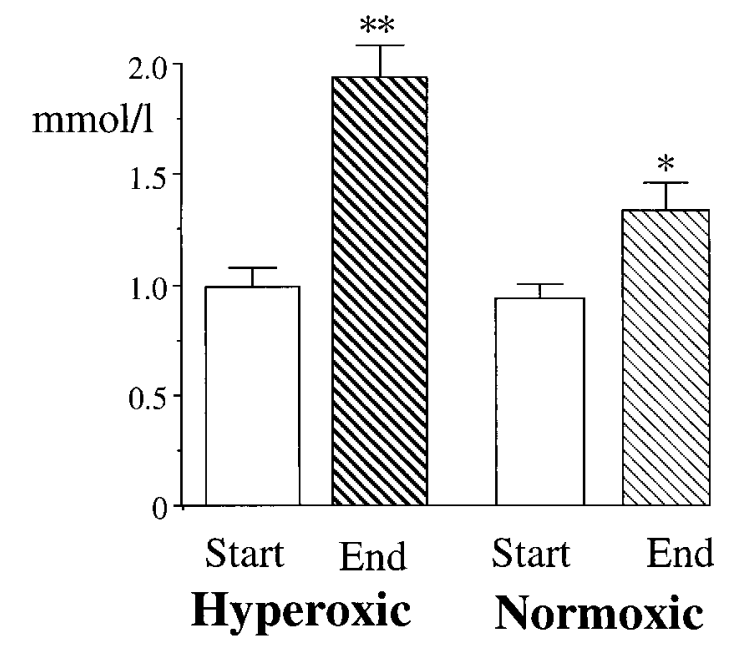

$*=\mathrm{p}=0.01$ vs. Hyperoxic

$* *=p=0.0001$ vs. Start

Fig. 4. Level of antioxidants in coronary sinus blood at the start and end of CPB in comparison of patients undergoing hyperoxic $\left(\mathrm{PO}_{2}=400 \mathrm{~mm} \mathrm{Hg}\right)$ or normoxic $\left(\mathrm{PO}_{2}=140 \mathrm{~mm} \mathrm{Hg}\right) \mathrm{CPB}$.

Creatine kinase increased 25-fold (hyperoxic) and 12-fold (normoxic) at the end of CPB compared with start-CPB values $(p=0.0001$ and 0.0002$)$. End-CPB values were higher in the hyperoxic group $(p=0.002$ vs normoxic). The absolute values are shown in Fig. 2.

Lactic dehydrogenase increased 570\% (hyperoxic) and $331 \%$ (normoxic) at the end of CPB compared with start-CPB values $(p=0.0001)$. Patients in the hyperoxic group had higher values $(p=$ 0.003 vs normoxic). The absolute values are shown in Fig. 3.

Levels of antioxidants increased $97 \%$ (hyperoxic; $p=0.0001$ ) and $48 \%$ (normoxic; $p=0.06$ ) at the end of CPB compared with start-CPB values. $\mathrm{Pa}-$ tients in the hyperoxic group had higher values $(p=$ 0.01 vs normoxic). The absolute values are shown in Fig. 4.

Malondialdehyde increased 1.3-fold (hyperoxic; $p=0.0001$ ) and 0.5 -fold (normoxic; $p=0.08$ ) after $\mathrm{CPB}$ compared with start-CPB values. End-CPB values were higher in the hyperoxic group $(p=0.005$ vs normoxic). The absolute values are shown in Fig. 5.

Nitrate was unchanged after $\mathrm{CPB}$ in the hyperoxic group but was reduced in normoxic patients $(p=$ 0.002 vs pre-CPB and vs hyperoxic). The absolute values are shown in Fig. 6.

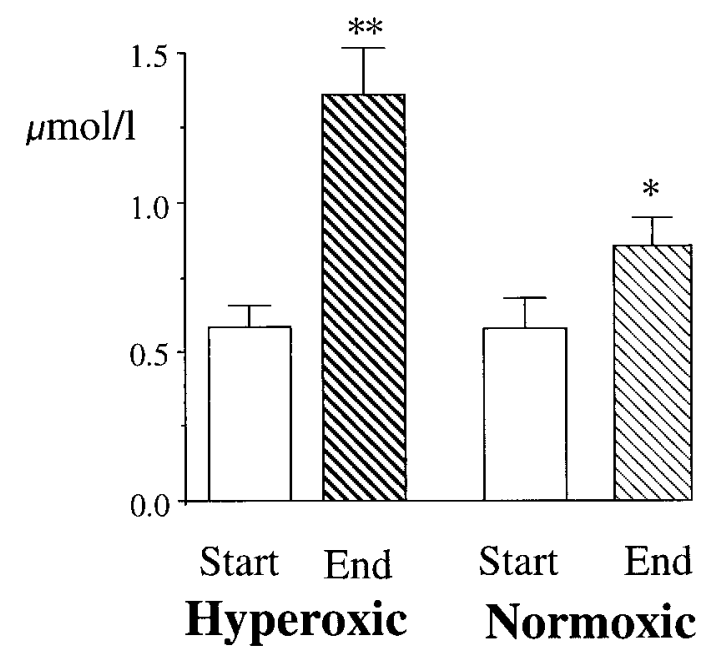

$*=\mathrm{p}=0.005$ vs. Hyperoxic

$* *=p=0.0001$ vs. Start

Fig. 5. Malondialdehyde in coronary sinus blood at the start and end of $\mathrm{CPB}$ in comparison of patients undergoing hyperoxic $\left(\mathrm{PO}_{2}=400 \mathrm{~mm} \mathrm{Hg}\right)$ or normoxic $\left(\mathrm{PO}_{2}=\right.$ $140 \mathrm{~mm} \mathrm{Hg}$ ) CPB.

Glucose levels after CPB were significantly increased at the end of CPB $(117 \pm 6$ vs $251 \pm 9 \mathrm{mg} / \mathrm{dl}$ [hyperoxic], $134 \pm 9 \mathrm{vs} 289 \pm 11 \mathrm{mg} / \mathrm{dl}$ [normoxic]; $p=0.0001$ vs start-CPB). The normoxic patients had higher values at the end of CPB ( $p=0.005$ vs hyperoxic).

Systemic venous levels of lactate, $\mathrm{pH}, \mathrm{Po}_{2}$, and $\mathrm{PCO}_{2}$ at the end of $\mathrm{CPB}$ showed no difference between groups. The absolute values are shown in Table II.

Cardiopulmonary values. Cardiac output measured at a left atrial pressure of 5 to $7 \mathrm{~mm} \mathrm{Hg}$ increased in both groups after CPB in comparison with the pre-CPB values $(p=0.06$ and 0.06$)$. Although there was a tendency toward higher postCPB values in normoxic patients $(6.5 \pm 0.6$ vs $5.7 \pm$ $0.5 \mathrm{~L} / \mathrm{min}$ ), there was no difference between groups $(p=0.1)$. Cardiac index $\left(\mathrm{L} / \mathrm{min} / \mathrm{m}^{2}\right)$ before and after CPB was similar between groups $(p=0.7$ and 0.6). The absolute values are shown in Fig. 7.

Vital capacity before CPB was the same in both groups. In both groups it was lower after CPB than before CPB. Normoxic patients had better vital capacity after CPB than the hyperoxic group ( $p=$ 0.008). Forced vital capacity before CPB displayed no differences between groups. After CPB there was a reduction in both groups, with higher absolute values in normoxic patients ( $p=0.02$ vs hyperoxic). 


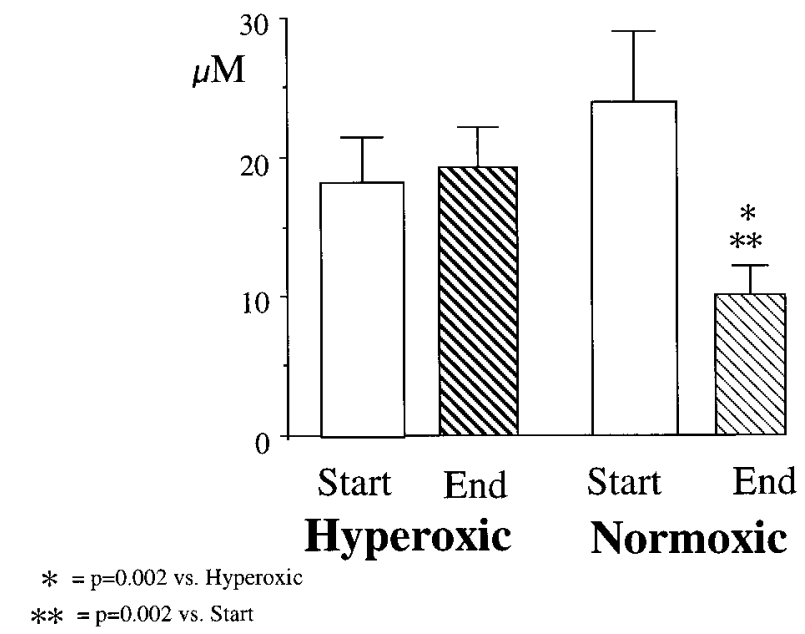

Fig. 6. Nitrate in coronary sinus blood at the start and end of $\mathrm{CPB}$ in comparison of patients undergoing hyperoxic $\left(\mathrm{Po}_{2}=400 \mathrm{~mm} \mathrm{Hg}\right)$ or normoxic $\left(\mathrm{Po}_{2}=140 \mathrm{~mm} \mathrm{Hg}\right)$ CPB.

The $1 \%$ vital capacity was severely decreased after hyperoxic CPB ( $p=0.0001$ vs pre-CPB and $p=$ 0.005 vs normoxic $\mathrm{CPB}$ ).

Maximal expiratory flow also was reduced in patients undergoing hyperoxic $\mathrm{CPB}(p=0.0001$ vs before $\mathrm{CPB})$ and displayed no changes in normoxic patients ( $p=0.8$ and $p=0.003$ vs hyperoxic patients). The absolute values are displayed in Table III.

Pulmonary vascular resistance was reduced after CPB in both groups $(p=0.2$ and 0.08$)$. There was no significant difference between groups. The absolute values are displayed in Table III.

\section{Discussion}

Hyperoxic CPB is widely used during surgical repair of hypoxic immature and normoxic adult hearts. The results of the current study indicate that this practice may expose the heart to oxidative damage resulting in enzyme release and lipid peroxidation. The observed hyperoxic oxygenation injury in normoxic adult hearts is similar to the reoxygenation injury of hypoxic immature hearts supported by CPB. ${ }^{1,2,14}$ The damaging potential of hyperoxic $\mathrm{CPB}$ can be limited markedly by reduced $\mathrm{PO}_{2}$ management (normoxic reoxygenation). This new strategy of normoxic CPB may be used to surgical advantage during cardiac operations in both children and adults.

A widely known example of the damaging effect of hyperoxia is retrolental fibroplasia in premature

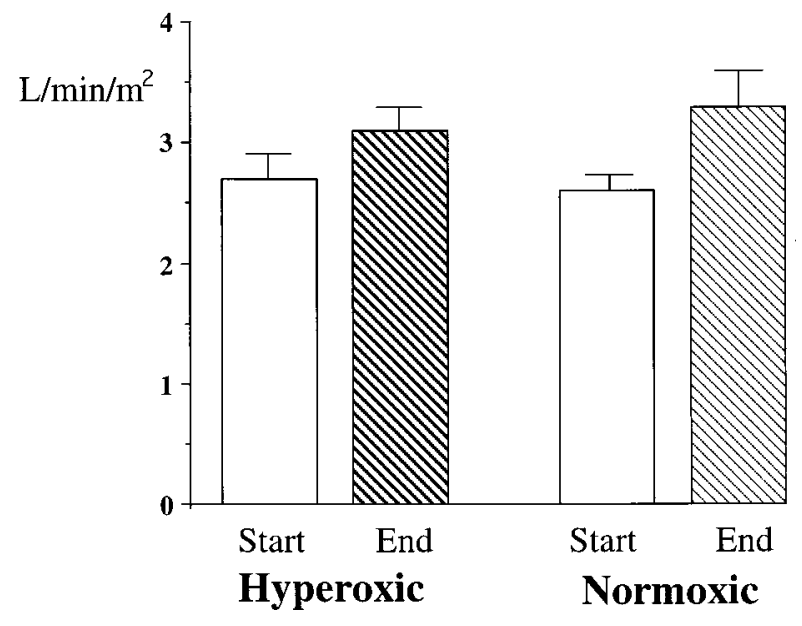

Fig. 7. Cardiac index before and after $\mathrm{CPB}$ in comparison of patients undergoing hyperoxic $\left(\mathrm{PO}_{2}=400 \mathrm{~mm} \mathrm{Hg}\right)$ or normoxic $\left(\mathrm{PO}_{2}=140 \mathrm{~mm} \mathrm{Hg}\right) \mathrm{CPB}$.

infants treated with high oxygen levels during ventilator support. ${ }^{19}$ Previous studies of the hypoxic immature heart suggested the existence of the damaging potential of high oxygen levels during extracorporeal circulation. ${ }^{1,2,14}$ Support for these findings stems from clinical studies of cyanotic children with tetralogy of Fallot having lipid peroxidation after the start of $\mathrm{CPB}{ }^{3}$ Additionally, there is evidence of myocardial dysfunction in infants in whom extracorporeal membrane oxygenation is used, despite absence of surgical ischemia. ${ }^{4}$ Despite the known damaging potential of high oxygen levels, $\mathrm{CPB}$ is commonly constituted in a hyperoxic fashion. And although several adverse effects of CPB (i.e., complement activation, release of PMN elastase and tumor necrosis factor, oxygen-derived free radical production) have already been addressed, the influence of hyperoxia during extracorporeal circulation has yet to be established. ${ }^{20,21} \mathrm{CPB}$ itself can lead to the production of damaging oxygen-derived free radicals. ${ }^{20}$ Highly cytotoxic reduced oxygen species $\left(\mathrm{O}_{2}{ }^{-}, \mathrm{H}_{2} \mathrm{O}_{2}\right.$ and $\left.\cdot \mathrm{OH}\right)$ play a central part in oxygenmediated injury. ${ }^{5}$ During normal metabolism, the cell protects itself from these products by ubiquitous endogenous free radical scavengers, which may be depleted by severe stress (hypoxia, ischemia). Thereafter, the burst of free radical production that occurs with the onset of reoxygenation or hyperoxia overwhelms the scavenging capacity of the reduced cellular defense system. ${ }^{22}$ Support for this observation stems from direct evidence of these toxic oxygen species with spin trapping and by avoiding 
Table II. Venous lactate, $\mathrm{pH}, \mathrm{PO}_{2}$, and $\mathrm{PCO}_{2}$ levels at the beginning and the end of hyperoxic or normoxic $C P B$

\begin{tabular}{|c|c|c|c|c|c|c|c|}
\hline & \multicolumn{3}{|c|}{ Hyperoxic } & \multicolumn{3}{|c|}{ Normoxic } & \multirow[b]{2}{*}{$p$ Value* } \\
\hline & Beginning & End & $p$ Value & Beginning & End & $p$ Value & \\
\hline Lactate $(\mathrm{mg} / \mathrm{dl})$ & $44.4 \pm 5.0$ & $20.8 \pm 1.3$ & 0.001 & $37.3 \pm 3.9$ & $17.7 \pm 1.5$ & 0.0001 & 0.3 \\
\hline $\mathrm{pH}$ & $7.35 \pm 0.02$ & $7.34 \pm 0.01$ & 0.08 & $7.33 \pm 0.01$ & $7.35 \pm 0.01$ & 0.1 & 0.2 \\
\hline $\mathrm{Po}_{2}(\mathrm{~mm} \mathrm{Hg})$ & $63 \pm 5$ & $45 \pm 2$ & 0.0001 & $59 \pm 2$ & $43 \pm 4$ & 0.0001 & 0.2 \\
\hline $\mathrm{PCO}_{2}(\mathrm{~mm} \mathrm{Hg})$ & $43 \pm 1$ & $46 \pm 2$ & 0.08 & $46 \pm 1$ & $47 \pm 1$ & 0.6 & 0.8 \\
\hline
\end{tabular}

$C P B$, cardiopulmonary bypass, normal range for lactate $(9.6$ to $17.1 \mathrm{mg} / \mathrm{dl})$.

*Absolute values at the end of CPB in comparison between groups.

oxygenation injury with antioxidants. ${ }^{9,22} \mathrm{We}^{8,23}$ confirmed these observations recently by showing a positive effect of cardioplegic enrichment, or prime supplementation with antioxidants to reduce reoxygenation injury in hypoxic immature piglet hearts.

Instead of treatment with antioxidants, it is conceivable that oxygen-derived free radicals can be avoided by lowering $\mathrm{PO}_{2}$ during extracorporeal circulation. The production of toxic oxygen species is proportionate to $\mathrm{Po}_{2} \cdot{ }^{7,11,24}$ Hyperoxemia sharply elevates the amount of oxygen dissolved in the membrane lipid matrix, thereby enhancing the possibility of oxygen interaction with reduced electron carriers and accentuating free radical production. ${ }^{24}$ In an experimental animal model without $\mathrm{CPB}$, Hearse, Humphrey, and Bullock ${ }^{12}$ have shown that myocardial damage that occurs with reoxygenation is highly depended on $\mathrm{PO}_{2}$ and that lowering oxygen levels will result in reduced creatine kinase release. It is conceivable that the reoxygenation injury becomes exaggerated when hypoxic myocardium is exposed abruptly to high $\mathrm{PO}_{2}$, as occurs when $\mathrm{CPB}$ is started. ${ }^{1}$ Similar to these observations, the results of the present study suggest the existence of an oxygenation injury in normoxic adult hearts on CPB. Compared with the start of $\mathrm{CPB}$, there was a significant increase in PMN elastase, creatine kinase, lactic dehydrogenase, and malondialdehyde, as well as reduced antioxidants at the end of the extracorporeal circulation. In contrast, applying normoxic CPB resulted in a significant improvement within these parameters. It is speculated that further reduction of $\mathrm{PO}_{2}$ during $\mathrm{CPB}(100 \mathrm{~mm} \mathrm{Hg})$ will lead to further improvement in results. This hypothesis is based on the observation that reoxygenation injury is reducible by controlling oxygen levels in CPB prime and blood cardioplegic solutions to $100 \mathrm{~mm}$ $\mathrm{Hg}$, to apply normoxia during the initial reoxygenation period. ${ }^{14}$ Furthermore, for the first time, we described a new method of "controlled reoxygen- ation" in which CPB is started with ambient $\mathrm{Po}_{2}(30$ $\mathrm{mm} \mathrm{Hg}$ ) and normoxic reoxygenation is begun at the time of cardioplegic arrest. ${ }^{25}$ Applying this method, we were able to avoid biochemical evidence of reoxygenation injury and to present almost complete functional recovery in previously hypoxic hearts. ${ }^{2}$ These findings and the results of the current study reinforce the hypothesis that oxygenation injury is dependent on $\mathrm{PO}_{2}$ and confirm the salutary effect of avoiding hyperoxia.

A second pathway of oxidant injury was proposed by Beckman and associates, ${ }^{6}$ whereby superoxide anion and NO interact to form cytotoxic oxygen species. Furthermore, NO generation is dependent on $\mathrm{PO}_{2}$ level. ${ }^{26}$ In cyanotic immature hearts we demonstrated a burst of $\mathrm{NO}$ at the onset of $\mathrm{CPB}$ associated with oxidant damage and myocardial dysfunction, which could be ameliorated by NO inhibition. ${ }^{27}$ Additionally, lowering oxygen levels in the circuit of the extracorporeal circulation and in blood cardioplegic solution limited NO release. ${ }^{25}$ In the present study, controlling the rate of introduction of molecular oxygen at the start of CPB reduced NO levels when compared with unchanged high values after hyperoxia. It is speculated that excess $\mathrm{NO}$ reacts with oxygen and generates $\mathrm{OONO}^{-}$, which then decomposes to generate highly toxic $0_{2}$ and $\mathrm{N}_{2}$ intermediates that produce lipid peroxidation. As in previous studies, reduced NO levels were accompanied by impaired malondialdehyde (lipid peroxidation), reduced creatine kinase release, and preserved antioxidant reserve capacity. ${ }^{2,14,25}$ However, the role of $\mathrm{NO}$ in cardiac oxygenation injury on $\mathrm{CPB}$ has to be addressed further. The present clinical study was purely observational and was not undertaken to investigate underlying mechanisms, as is the aim of basic research.

The synergism of damage related to oxygenderived free radicals and neutrophil elastase has been reported. ${ }^{28}$ We measured PMN elastase, which 
Table III. Pulmonary function 1 day before and 5 days after hyperoxic or normoxic CPB (pulmonary vascular resistance is measured before and after $C P B$ )

\begin{tabular}{lcccccccc}
\hline & \multicolumn{3}{c}{ Hyperoxic } & & \multicolumn{3}{c}{ Normoxic } \\
\cline { 2 - 3 } & Before & After & $p$ Value & & Before & After & $p$ Value & $p$ Value* \\
\hline VC & $98 \pm 6$ & $66 \pm 2$ & 0.0001 & & $98 \pm 7$ & $81 \pm 1$ & 0.02 & 0.008 \\
FVC & $99 \pm 2$ & $68 \pm 5$ & 0.0001 & & $98 \pm 4$ & $83 \pm 4$ & 0.02 & 0.02 \\
FEV $_{1}$ & $97 \pm 4$ & $63 \pm 10$ & 0.0001 & & $98 \pm 6$ & $93 \pm 4$ & 0.3 & 0.005 \\
MEF $_{50}$ & $87 \pm 7$ & $46 \pm 4$ & 0.0001 & & $88 \pm 9$ & $82 \pm 12$ & 0.8 & 0.03 \\
PVRI & $275 \pm 25$ & $232 \pm 19$ & 0.2 & & $276 \pm 38$ & $207 \pm 26$ & 0.08 & 0.4
\end{tabular}

$C P B$, Cardiopulmonary bypass; $V C$, vital capacity (\% norm); $F V C$, forced vital capacity (\% norm); $F E V_{1}$, forced expiratory volume during the first second (\% norm); $M E F_{50}$, maximum expiratory flow at $50 \%$ of $\mathrm{VC} \mathrm{( \%} \mathrm{norm);} \mathrm{\%} \mathrm{norm,} \mathrm{normal} \mathrm{value} \mathrm{of} \mathrm{healthy} \mathrm{individuals} \mathrm{of} \mathrm{equal} \mathrm{sex,} \mathrm{age,} \mathrm{and} \mathrm{body} \mathrm{surface} \mathrm{area;}$ PVRI, pulmonary vascular resistance index $\left(\mathrm{mm} \mathrm{Hg} \times \min \times \mathrm{L}^{-1} \times \mathrm{kg}\right)$

*Absolute values after CPB in comparison between groups.

was elevated after hyperoxic $\mathrm{CPB}$, supporting former reports in which, however, $\mathrm{PO}_{2}$ levels during $\mathrm{CPB}$ are not mentioned. ${ }^{21}$ On the contrary, normoxic $\mathrm{CPB}$ resulted in a significantly impaired increase of PMN elastase, which was accompanied by less lipid peroxidation and preserved antioxidant levels. To our knowledge, this is the first time that a $\mathrm{PO}_{2}$-dependent elastase release on CPB is described. Oxygen-dependent reduction of lipid peroxidation in this investigation confirms our previous findings, as well as those of others. ${ }^{2,7,11,14,22,23,27}$

No significant difference between groups was found in post-CPB contractility. However, cardiac performance was measured at one low point of the Starling function curve. It is speculated that applying more sensitive methods (conductance catheter) or measuring cardiac performance at different preload levels (Starling curves) may reveal impaired function after hyperoxic CPB. This hypothesis is based on our previous studies, in which severely damaged hearts after reoxygenation injury could be weaned from CPB without inotropic support and had a normal cardiac output at low filling pressures. However, measuring contractility with conductance catheter or increasing stress by augmenting preload suggested a severely impaired cardiac performance. ${ }^{1,2}$ In contrast, after normoxic or controlled reoxygenation, these same measurements indicated complete ventricular recovery. ${ }^{14,25}$

We acknowledge that the results of the present study are inconclusive in terms of cardiac performance. However, even though short-term benefits of normoxic CPB may not be immediately obvious, long-term changes of lipid peroxidation and free radical damage is currently unknown and will have to be studied. However, there is no rationale to expose patients to an obvious biochemical injury whose long-term effect is yet to be determined and which easily can be avoided by applying more physiologic methods. We look to further clinical studies using the described methods to prove whether biochemical oxygenation injury in normoxic adult hearts after hyperoxic $\mathrm{CPB}$ is accompanied by a relevant loss in performance.

Impaired lung function in patients undergoing hyperoxic CPB indicates that hyperoxia is not damaging to the heart alone but rather has a whole body effect, a theory that is supported by other reports. ${ }^{13,29}$ Leukocyte-originated oxygen free radical-related lipid peroxidation with subsequent lung injury after $\mathrm{CPB}$ has been reported; unfortunately the $\mathrm{PO}_{2}$ during $\mathrm{CPB}$ was not mentioned. ${ }^{29}$ Leukocyte depletion resulted in less injury. ${ }^{29}$ This finding supports our observation that reduced leukocytederived PMN elastase was associated with less lipid peroxidation and creatine kinase release. Again, further studies will clarify the effect of hyperoxia during CPB on organs other than the heart.

Our former findings of a reoxygenation injury in cyanotic immature hearts on hyperoxic CPB are supported by the present clinical study, which for the first time investigates the oxidative challenge of hyperoxia during cardiac operations in adults, comparing it with a normoxic management. ${ }^{30}$ Former findings of the damaging effect of $\mathrm{CPB}$ may be, at least in part, more related to hyperoxia than to $\mathrm{CPB}$ itself. We found convincing evidence that reduced $\mathrm{PO}_{2}$ during $\mathrm{CPB}$ is crucial in avoiding oxygen-derived free radical damage and lipid peroxidation. Hyperoxia is not physiologic, it is damaging to all organs, and it is not required during extracorporeal circulation, where oxygen delivery can be adjusted easily by augmenting pump flow. The safety of normoxic $\mathrm{CPB}$ is confirmed by measurement of venous lactate, $\mathrm{pH}, \mathrm{Po}_{2}$, and $\mathrm{PCO}_{2}$, showing no differences between groups. It is suggested that, 
contrary to conventional practice, $\mathrm{CPB}$ in hypoxic immature hearts as well as in normoxic adult hearts is instituted in a normoxic fashion to avoid oxygenation damage and lipid peroxidation.

We thank Dr. Olschewski, of the statistical department of the Albert-Ludwigs-University Freiburg, for helping with the statistical analysis.

\section{REFERENCES}

1. Ihnken K, Morita K, Buckberg GD, et al. Studies of hypoxemic/reoxygenation injury: Without aortic clamping. II. Evidence for reoxygenation damage. J Thorac Cardiovasc Surg 1995;110:1171-81.

2. Morita K, Ihnken K, Buckberg GD, Sherman MP, Young $\mathrm{HH}$, Ignarro LJ. Role of controlled cardiac reoxygenation in reducing nitric oxide production and cardiac oxidant damage in cyanotic infantile hearts. J Clin Invest 1994;93:2658-66.

3. Del Nido PJ, Mickle DAG, Wilson GJ, et al. Evidence of myocardial free radical injury during elective repair of tetralogy of Fallot. Circulation 1987;76(Suppl):V174-9.

4. Hirschl RB, Heiss KF, Bartlett RH. Severe myocardial dysfunction during extracorporeal membrane oxygenation. J Pediatr Surg 1992;27:48-53.

5. Frank L, Massaro D. Oxygen toxicity. Am J Med 1980;69: 117-26.

6. Beckman JS, Beckman TW, Chen J, Marshall PA, Freeman BA. Apparent hydroxyl radical production by peroxynitrite: implications for endothelial injury from nitric oxide and superoxide. Proc Natl Acad Sci U S A 1990;87:1620-4.

7. Gauduel Y, Menasche P, Duvelleroy M. Enzyme release and mitochondrial activity in reoxygenated cardiac muscle: relationship with oxygen-induced lipid peroxidation. Gen Physiol Biophys 1989;8:327-40.

8. Ihnken K, Morita K, Buckberg GD, Sherman MP, Young HH. Studies of hypoxemic/reoxygenation injury: Without aortic clamping. VI. Counteraction of oxidant damage by exogenous antioxidants: $N$-(2-mercaptopropionyl)-glycine and catalase. J Thorac Cardiovasc Surg 1995;110:1212-20.

9. Garlick PB, Davies MJ, Hearse DJ, Slater TF. Direct detection of free radicals in the reperfused rat heart using electron spin resonance spectroscopy. Circ Res 1987;61:757-60.

10. Boveris A, Chance B. The mitochondrial generation of hydrogen peroxide: general properties and effect of hyperbaric oxygen. Biochem J 1973;134:707-16.

11. Littauer A, De Groot H. Release of reactive oxygen by hepatocytes on reoxygenation: three phases and role of mitochondria. Am J Physiol 1992;262:G1015-20.

12. Hearse DJ, Humphrey SM, Bullock GR. The oxygen paradox and the calcium paradox: Two facets of the same problem? J Mol Cell Cardiol 1987;10:641-68.

13. Deneke SM, Fanburg BL. Normobaric oxygen toxicity of the lung. N Engl J Med 1980;303:76-86.

14. Ihnken K, Morita K, Buckberg GD. Studies of hypoxemic/ reoxygenation injury: With aortic clamping. XI. Cardiac advantages of normoxemic versus hyperoxemic management during cardiopulmonary bypass. J Thorac Cardiovasc Surg 1995;110:1255-64.

15. Buckberg GD. Strategies and logic of cardioplegic delivery to prevent, avoid, and reverse ischemic and reperfusion damage. J Thorac Cardiovasc Surg 1987;93:127-39.

16. Miller NJ, Rice-Evans C, Davies MJ, Gopinathan V, Milner A. A novel method for measuring antioxidant capacity and its application to monitoring the antioxidant status in premature neonates. Clin Sci 1993;84:407-12.

17. Wong SHY, Knight JA, Hopfer SM, et al. Lipoperoxides in plasma as measured by liquid-chromatographic separation of malondialdehyde-thiobarbituric acid adduct. Clin Chem 1987;33:214-20.

18. Green LC, Wagner DA, Glogowski J, Skipper PL, Wishnok JS, Tannenbaum SR. Analysis of nitrate, nitrite, and (15N) nitrate in biological fluids. Anal Biochem 1982;126:131-8.

19. Jacobson RM, Feinstein AR. Oxygen as a cause of blindness in premature infants: "autopsy" of a decade of errors in clinical epidemiologic research. J Clin Epidemiol 1992;45: 1265-87.

20. Cavarocchi NC, England MD, Schaff HV, et al. Oxygen free radical generation during cardiopulmonary bypass: correlation with complement activation. Circulation 1986;74(Suppl): III130-3.

21. Butler J, Pillai R, Rocker GM, Westaby S. Effect of cardiopulmonary bypass on systemic release of neutrophil elastase and tumor necrosis factor. J Thorac Cardiovasc Surg 1993; 105:25-30.

22. Dhaliwal H, Kirshenbaum LA, Randhawa AK, Singal PK. Correlation between antioxidant changes during hypoxia and recovery on reoxygenation. Am J Physiol 1991;261:H632-8.

23. Morita K, Ihnken K, Buckberg GD, Matheis G, Sherman MP, Young HH. Studies of hypoxemic/reoxygenation injury: With aortic clamping. X. Exogenous antioxidants to avoid nullification of the cardioprotective effects of blood cardioplegia. J Thorac Cardiovasc Surg 1995;110:1245-54.

24. Boveris A. Mitochondrial production of superoxide radical and hydrogen peroxide. Adv Exp Med Biol 1977;78:61-82.

25. Morita K, Ihnken K, Buckberg GD. Studies of hypoxemic/ reoxygenation injury: With aortic clamping. XII. Delay of cardiac reoxygenation damage in the presence of cyanosis: a new concept of controlled cardiac reoxygenation. J Thorac Cardiovasc Surg 1995;110:1265-73.

26. Rengasamy A, Johns RA. Characterization of endotheliumderived relaxing factor/nitric oxide synthase from bovine cerebellum and mechanism of modulation by high and low oxygen tensions. J Pharmacol Exp Ther 1991; 259:310-6.

27. Morita K, Matheis G, Buckberg GD, et al. Studies of hypoxemic/reoxygenation injury: Without aortic clamping. V. Role of the L-arginine-nitric oxide pathway: the nitric oxide paradox. J Thorac Cardiovasc Surg 1995;110:1200-11.

28. Welbourn CRB, Goldman G, Paterson IS, Valeri CR, Shepro D, Hechtman HB. Neutrophil elastase and oxygen radicals: synergism in lung injury after hindlimb ischemia. Am J Physiol 1991;29:H1852-6.

29. Bando K, Pillai R, Cameron DE, et al. Leukocyte depletion ameliorates free radical-mediated lung injury after cardiopulmonary bypass. J Thorac Cardiovasc Surg 1990;99:873-7.

30. Ihnken K, Winkler A, Beyersdorf F, Neidhart G, Winkelmann B, Unkelbach U, et al. Reduction of oxidative damage and nitric oxide on cardiopulmonary bypass by controlling $\mathrm{pO}_{2}$ during open heart surgery. Circulation 1995;92(Suppl): I763-4. 